THERESA RAQUEL DE OLIVEIRA RAMALHO

\title{
OS LEUCOTRIENOS NO DIABETES TIPO 1
}

Tese apresentada ao programa de Pós-graduação em Imunologia do Instituto de Ciências Biomédicas da Universidade de São Paulo, para obtenção do título de doutor em Ciências.

São Paulo

2018 
THERESA RAQUEL DE OLIVEIRA RAMALHO

\section{OS LEUCOTRIENOS NO DIABETES TIPO 1}

Tese apresentada ao programa de Pós-graduação em Imunologia do Instituto de Ciências Biomédicas da Universidade de São Paulo, para obtenção do título de doutor em Ciências.

Área de concentração: Imunologia Orientadora Profa Dra Sonia Jancar

Co-orientador $\mathrm{Dr}$ Luciano

Filgueiras

Versão Original

São Paulo 


\section{RESUMO}

Ramalho, Theresa Raquel de Oliveira. Os Leucotrienos no Diabetes tipo 1. 2018. Tese (Doutorado em Ciências com ênfase em Imunologia). Instituto de Ciências Biomédicas. Universidade de São Paulo, São Paulo, 2018.

O diabetes tipo 1 (DT1) é uma doença metabólica associada a uma inflamação sistêmica de baixo grau, responsável por importantes co-morbidades associadas. Nosso grupo demonstrou que esta inflamação depende dos níveis plasmáticos aumentados de leucotrienoB4 (LTB4), o qual estimula o eixo Myd88/STAT1 amplificando a resposta dos receptores TLR/IL1 $\beta$ em macrófagos. Isso caracteriza o programa pró-inflamatório M1 nestas células, que requer energia proveniente da glicólise e produz substancias tóxicas como espécies reativas de oxigênio (ROS) e óxido nítrico (NO). Isto pode ser minimizado pela respiração mitocondrial desacoplada à síntese de ATP no metabolismo lipídico. Assim, na primeira parte do trabalho os macrófagos de camundongos (C57BI/6) DT1, expressaram níveis elevados de marcadores de oxidação de ácidos graxos, o que não foi observado em macrófagos de camundongos diabéticos tratados com o antagonista de LTB4 (u75302). Além disso, o u75302 também reduziu a expressão aumentada de CD36, receptor envolvido na captação de lipídios, assim como aumento de lipídios intracelulares nestas células. Os elevados níveis de triglicérides e ácidos graxos presentes no plasma dos diabéticos também foram reduzidos pelo antagonista u75302, e isso foi consistente com o aparecimento de marcadores de lipólise (Prdm16 e Fgf21) no tecido adiposo branco destes animais. Da mesma forma, u75302 reduziu o consumo de oxigênio dos macrófagos de animais diabéticos. Isso foi consistente com os resultados obtidos em macrófagos de camundongos diabéticos deficientes da UCP1, os quais apresentaram maior peso corporal, maior massa de gordura e metabolismo mitocondrial mais baixo do que diabéticos WT. A perda de gordura também foi recuperada pelo tratamento com u75302 indicando o envolvimento do LTB4 na perda de adiposidade e dislipidemia em DT1. Na segunda parte do trabalho, confirmamos a participação dos leucotrienos na inflamação sistêmica em DT1 induzida por estreptozotocina. Camundongos (129SvE) diabéticos apresentaram níveis sistêmicos elevados das citocinas e este aumento não ocorreu em 129Sve deficientes da enzima 5-lipoxigenase $\left(5 \mathrm{LO}^{-1}\right)$, responsável pela síntese de leucotrienos. A

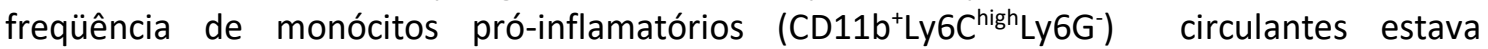
aumentada em camundongos diabéticos WT mas não nos $5 \mathrm{LO}^{\%}$. Macrófagos peritoneais residentes de camundongos diabéticos também apresentaram um fenótipo semelhante ao M1 classicamente ativado (alta expressão de Nos2 e Stat1, e alta produção de NO), que não foi revertido com o estímulo de IL4 in vitro ou in vivo. Por outro lado, os macrófagos dos $5 \mathrm{LO}^{-}$ diabéticos apresentaram o fenótipo de macrófagos M2 alternativamente ativados (alta expressão de Ym1 e Arg1, e alta atividade de arginase). Os animais WT diabéticos tiveram cicatrização deficiente que se correlacionou com uma baixa freqüência de macrófagos M2 $\left(\mathrm{CD}^{2} 5^{+} \mathrm{F} 4 / 80^{+} \mathrm{CD} 206^{+}\right)$nas lesões cutâneas comparado com os demais grupos. Juntos, estes dados sugerem que no DT1 os leucotrienos contribuem para a inflamação sistêmica e reprogramação dos monócitos e macrófagos para perfil inflamatório e isto está associado com aumento do metabolismo energético nestas células. Estas alterações induzidas nos macrófagos pelos níveis elevados de leucotrienos, particularmente LTB4, se correlacionam com a cicatrização deficiente, com a perda de gordura e hiperlipidemia nos camundongos DT1, sugerindo que o LTB4 possa ser um alvo terapêutico no diabetes.

Palavras-chave: Diabetes tipo 1, leucotrienos, leucotrieno B4, macrófagos, metabolismo energético, imunometabolismo. polarização de macrófagos, cicatrização. 


\section{ABSTRACT}

Ramalho, Theresa Raquel de Oliveira. Leukotrienes in Type 1 Diabetes. 2018. Tese (Doutorado) - Instituto de Ciências Biomédicas. Universidade de São Paulo, São Paulo, 2018.

Type 1 diabetes (T1D) is a metabolic disease associated to systemic low grade inflammation, which has an important role in co-morbidities. Our group showed that this inflammation depends on the high systemic levels of leukotriene-B4 (LTB4), which stimulateds MyD88/Stat1 axis, amplifying TLR/IL1 $\beta$ response in macrophages. This characterizes pro inflammatory M1 program, which requires energy from glycolysis, and produces harmful molecules, such as reactive oxygen species (ROS) and nitric oxide (NO). This can be mitigated by mitochondrial respiration uncoupled to ATP synthesis in lipid metabolism. Therefore, in the first part of this study, macrophages from T1D mice (C57BI/6) expressed high levels of fatty acid oxidation markers, which was not observed in macrophages from T1D mice treated with LTB4 receptor antagonis, u75302. Moreover, u75302 also reduced the high expression od CD36, a receptor involved in lipids uptake, and also reduced intracellular lipids in these cells. The high levels of triglycerides in diabetic plasma were reduced by 475302 , and this is consistent with lipolysis markers (Prdm16 and Fgf21) in white adipose tissue of these mice. This was also consistent with results obtained in macrophages from diabetic UCP1 deficient mice, which had higher body weight and lower mitochondrial metabolism then WT diabetics. Fat loss was also recovered by u75302 treatment, indicating an involvement of LTB4 in adiposity loss and dyslipidemia in T1D. In the second part of this study, we confirmed leukotrienes participation in systemic inflammation in T1D streptozotocin-induced. T1D mice (129SvE) increased systemic levels of cytokines, which was not observed in T1D 5lipoxygenase deficient mice $\left(5 \mathrm{LO}^{-/}\right)$. The frequency of pro inflammatory monocytes $\left(\mathrm{CD} 11 \mathrm{~b}^{+}\right.$Ly6 $\left.\mathrm{C}^{\text {high }} \mathrm{Ly}_{6 \mathrm{G}}\right)$ ) was increased in WT diabetic mice, but not in $5 \mathrm{LO}^{-/}$. Resident peritoneal macrophages in diabetics had a phenotype similar to M1 classically activated (Nos2 and Stat1 highly expressed, and high production of NO), which was not reversed by IL-4 stimulation in vitro and in vivo. On the other hand, macrophages from diabetic $5 \mathrm{LO}^{-/-}$had a phenotype $\mathrm{M} 2$ alternatively activated ( $\mathrm{Ym} 1$ and Arg1 highly expressed, and high arginase activity). WT diabetic mice had a defective wound healing, which was related to low frequency of M2 $\left(C D 45^{+} \mathrm{F} 4 / 80^{+} \mathrm{CD} 206^{+}\right)$macrophages in cutaneous wounds, compared to the other groups. All together, our data suggest that in T1D leukotrienes induce systemic inflammation, and reprogram pro inflammatory phenotype in monocytes and macrophages, and this is related to increased energetic metabolism in these cells. These alteration in macrophages due to leukotrienes effects, mainly LTB4, are correlated to defective healing, with fat loss, and dyslipidemia in T1D mice, suggesting that LTB4 can be a therapeutic target in diabetes.

Keywords: type 1 diabetes, leukotrienes, leukotriene B4, macrophages, energetic metabolism, immunemetabolism, macrophages polarization, wound healing. 


\section{INTRODUÇÃO}

\subsection{0 diabetes tipo 1}

O diabetes tipo 1 é uma doença metabólica caracterizada por alterações no metabolismo de carboidratos, lipídios e proteínas. Esta doença se desenvolve devido a uma resposta auto-imune contra as células $\beta$ do pâncreas, o que leva a falha na produção de insulina. Devido a isso, pacientes com diabetes tipo 1 são dependentes da reposição de insulina para controle da glicemia ${ }^{1}$.

Apesar disso, os pacientes diabéticos quando não diagnosticados, ou com mau controle da glicemia, podem apresentar sérias manifestações em resposta à hiperglicemia. Além disso, pacientes em reposição prolongada com insulina podem desenvolver resistência a insulina ${ }^{2}$. De acordo com os dados do Atlas da Federação Internacional de Diabetes (IDF Atlas) de 2017, a incidência de diabetes tipo 1 está aumentando por volta de 3 a $4 \%$ a cada ano, principalmente entre crianças. Porém, as causas para este aumento anual ainda estão sob investigação ${ }^{3}$.

Pacientes diabéticos com mau controle da hiperglicemia apresentam uma substancial redução de peso, devido à perda de adiposidade ${ }^{4}$. Curiosamente, estes pacientes também apresentam elevados níveis de triglicérides no sangue, sendo a dislipidemia a principal causa para o desenvolvimento de doenças cardiovasculares ${ }^{5}$. Considerando que no diabetes as alterações do metabolismo lipídico acarretam em modificações no metabolismo dos monócitos e macrófagos que adquirem um perfil proinflamatório que leva ao estabelecimento de uma inflamação crônica de baixa intensidade (LGI, do inglês low grade inflammation) ${ }^{6 ;} 7$, neste trabalho investigamos o papel dos leucotrienos nas alterações metabólicas e inflamatórias assim como em uma comorbidade importante do diabetes que é a cicatrização deficiente. Nos tópicos abaixo desta introdução pretendemos dar os subsídios da literatura que suportam a hipótese deste trabalho.

\subsection{0 metabolismo lipídico sistêmico}

A função primária do metabolismo lipídico é transportar lipídios, advindos da alimentação ou da perda do tecido adiposo, para serem usados em tecidos periféricos, 
ou direcionados para reciclagem ou ablação no fígado. O metabolismo lipídico é realizado por três vias que retroalimentam entre si: via exógena, via endógena e via do transporte reverso de colesterol. Na via exógena, quilomicrons advindos do intestino são liberados na linfa, entram na circulação e são estocados no tecido adiposo. No tecido adiposo, lipoproteínas lipases degradam o quilomicron em ácidos graxos e quilomicrons remanescentes, estes voltam para a circulação e entram no fígado para serem degradados em ácidos graxos e colesterol ${ }^{8}$.

$\mathrm{Na}$ via endógena, lipoproteínas de densidade muito baixa (VLDL) são exportadas do fígado para a circulação, por onde elas chegam até o tecido adiposo. No tecido adiposo, as VLDLs são degradadas novamente em ácidos graxos e VLDLs remanescentes (IDLs). O IDL depois é convertido a lipoproteínas de baixa densidade (LDLs) que voltam para a circulação para transferência de colesterol para tecidos periféricos, e voltam para o fígado. Na via do transporte reverso de colesterol, o excesso de colesterol retorna para o fígado através das lipoproteínas de alta densidade (HDL) para ser secretado na bile ${ }^{8 ; 9}$.

A insulina tem um papel central na regulação do metabolismo lipídico. No tecido adiposo, a insulina exerce função antilipolítica através da inibição da lipase, o que leva ao estoque de triglicérides nos adipócitos, e redução da liberação de ácidos graxos do tecido adiposo para a circulação. A insulina também inibe a produção de VLDL pelo fígado pela redução de ácidos graxos circulantes (devido à sua atividade antilipolítica), que são substratos para a VLDL ${ }^{10}{ }^{11}$. A insulina também é um potente ativador da lipoproteína lipase (LPL), que catabolizam lipoproteínas ricas em triglicérides e reduz, por consequiência, os níveis de triglicérides no plasma. A insulina também auxilia no clearance de LDL por aumentar a expressão do receptor B,E de LDL no fígado. Este hormônio também age no metabolismo de HDL pela ativação da atividade de enzimas lipases no fígado ${ }^{12}$.

Pacientes com diabetes tipo 1 com cetoacidose apresentam anormalidades nos níveis de lipídios devido à deficiência nos níveis de insulina. Isso está diretamente relacionado à redução do catabolismo de lipoproteínas ricas em triglicérides, e indução de hipertrigliceridemia ${ }^{13}$. Pacientes diabéticos tratados com insulina e com mau controle glicêmico apresentam desordens no metabolismo lipídico ${ }^{14 ;} 15$. Isso acontece devido à produção de VLDL estar aumentada e o catabolismo de lipoproteínas ricas em triglicérides não estar suficientemente reduzido, o que leva ao aumento na produção de LDL ${ }^{16}$. . As VLDLs são consideradas altamente aterogênicas em diversas patologias ${ }^{17}$. 
Além disso, neste caso, quando os níveis de glicose excedem a capacidade renal, a glicosúria leva à perda de água e desidratação crônica. Isso contribui negativamente para o balanço energético, de forma independente do consumo de energia pela alimentação ${ }^{18}$. Existem relatos de que mesmo em pacientes diabéticos com glicemia bem controlada, os nívei de HDL são elevados. A literatura tem sugerido que isso acontece em conseqüência do aumento da atividade da LPL lipase do fígado ${ }^{19}$.

$\mathrm{O}$ tecido adiposo exerce um papel fundamental no metabolismo lipídico. $\mathrm{Na}$ composição de gordura corporal existem dois tipos de tecido adiposo, o branco e o marrom. O tecido adiposo branco (WAT) é especializado em estocar triglicerídeos. Já o tecido adiposo marrom (BAT) utiliza os lipídios como fonte termogênica. No tecido adiposo marrom existe uma alta expressão e atividade de moléculas associadas à termogênese, como as proteínas desacopladoras (Uncoupling proteins, UCPs), portanto neste tecido o tipo de respiração predominante é a desacoplada da síntese de ATP ${ }^{20}$.

Muitas doenças crônicas, como obesidade, síndrome metabólica e lipodistrofia, induzem remodelamento do tecido adiposo branco. Na caquexia associada ao câncer, um exemplo de patologia em que existe perda do tecido adiposo branco, citocinas aumentam a taxa metabólica na gordura através da ativação de termogênese, e inibição de diferenciação de adipócitos ${ }^{21}{ }^{22}$.

Um fator que também está envolvido neste gasto energético é o aumento dos níveis de glucagon, em decorrência da ausência da insulina ${ }^{23}$. Trabalhos demonstraram que o glucagon tem habilidade em aumentar o consumo de oxigênio, pois o uso de somatostatina (uma droga que bloqueia a produção de glucagon) reduz o gasto energético em pacientes diabéticos ${ }^{24}$. Os altos níveis de glucagon induzem gliconeogênese, a qual contribui para um estado hipermetabólico no diabetes. Isso leva a um aumento na produção de glicose pelo fígado, o que contribui ainda mais para a hiperglicemia, glicosúria e perda de água ${ }^{25}$

Já foi demonstrado que a perda de peso em pacientes diabéticos se dá em decorrência de perda no músculo, porém recentemente foi demonstrado que esta perda de peso está mais fortemente atrelada à perda de gordura 4 .

Diversas doenças metabólicas que manifestam elevados níveis de lipídios no sangue mostram que a hiperlipidemia está associada com o desenvolvimento de LGI ${ }^{26}$; 27. Por exemplo, humanos com doenças cardiovasculares apresentam uma forte relação entre altos níveis de lipídios no sangue e um estado inflamatório em monócitos ${ }^{28}$. Já em 
pacientes com diabetes tipo 1 , que tem a hiperlipidemia como manifestação clínica ${ }^{29}$, os monócitos secretam citocinas inflamatórias de forma espontânea, como IL-6 e IL-1 $\beta$ 6.

\subsection{0 metabolismo energético nos macrófagos}

Os macrófagos são células bastante maleáveis, que podem adaptar sua fisiologia e função de acordo com o microambiente onde estão inseridas ${ }^{30}$. A adaptação fisiológica dos macrófagos altera o metabolismo destas células. Em condições homeostáticas, o ciclo glicolítico acontece de forma intacta e interage com outras vias metabólicas de forma equilibrada. A glicólise converte glicose em piruvato, o qual pode ser convertido a lactato, que é secretado. O piruvato também pode entrar no ciclo do ácido tricarboxílico (TCA) gerando NADH e FADH2 para a cadeia transportadora de elétrons na mitocôndria, levando à produção de ATP. Ácidos graxos quando oxidados também geram NADH e FADH2A. A glicose também alimenta a via das pentoses fosfato (PPP), que gera ribose para síntese de nucleotídeos, aminoácidos e NADPH. O NADPH é usado para a síntese de ácidos graxos, que utiliza citrato advindo do TCA. Os aminoácidos também podem alimentar o TCA, que também é importante para crescimento celular e síntese de proteínas ${ }^{31}$.

Em condições homeostáticas, os macrófagos captam lipoproteínas de densidade baixa (LDLs) e lipoproteínas de densidade muito baixa (VLDLs) via macropinocitose, fagocitose e receptores scavengers como o CD36. O colesterol livre e os ácidos graxos são gerados a partir da degradação de lipídios digeridos nos lisossomos. Este colesterol pode ser utilizado para formação de plataformas lipídicas (lipid rafts) na membrana plasmática e o acúmulo de colesterol citosólico pode ativar fatores de transcrição que induzem a expressão de transportadores do efluxo de colesterol ${ }^{32 ; 33}$. Já os ácidos graxos vão para a via oxidativa na mitocôndria onde eles são convertidos em produtos que a célula utiliza para geração de energia, como acetil-CoA, NADH e FADH2 ${ }^{34}$.

Inicialmente os ácidos graxos são convertidos a acil-CoA. Quando os ácidos graxos são de cadeia curta, eles entram de forma passiva na mitocôndria, mas quando são de cadeia média ou longa, eles são conjugados à carnitina por ação da enzima carnitina palmitoil transferase 1A (CPT1A) e são transportados para dentro da mitocôndria. Dentro da mitocôndria a enzima CPT2 remove a carnitina e a $\beta$-oxidação dos ácidos graxos acil-CoA acontece gerando acetyl-CoA, NADH e FADH2, que são 
subsequentemente usados no ciclo TCA e cadeia transportadora de elétrons para geração de $\operatorname{ATP}^{31 ; 35}$.

Além da síntese de ATP, a cadeia de transporte de elétrons também pode direcionar o efluxo de prótons de forma desacoplada à síntese de ATP, com participação das proteínas desacopladoras, ou uncoupling proteins. Neste caso, a síntese de ATP é convertida para síntese de calor. Inicialmente, estas moléculas foram bastante descritas no tecido adiposo marrom, em decorrência da função termogênica deste órgão. Posteriormente, viu-se que estas moléculas também exercem funções em outros órgãos como no tecido adiposo branco, e em células imunes como macrófagos ${ }^{36}$.

Sob estímulos inflamatórios, os macrófagos ativados requerem um aporte energético advindo da glicólise anaeróbia. Apesar de a glicólise anaeróbia produzir baixos níveis de ATP, esta reação acontece de forma rápida, por utilizar uma via menos complexa, gerando ATP em velocidade e quantidade suficiente para o macrófago permanecer vivo e ativo em respostas inflamatórias ${ }^{37}$. A glicólise aeróbia também pode estar atrelada ao perfil pró-inflamatório de macrófagos, pois a molécula de oxigênio, ao receber um elétron adicional, cria um íon superóxido, que, além de ter função microbicida, também é bastante tóxico para outras moléculas, o que caracteriza a nocividade das espécies reativas de oxigênio (ROS) ${ }^{38}$. Além disso, a glicólise também permite a redução de $\mathrm{NAD}+$ para $\mathrm{NADH}$, que é utilizado como co-fator para inúmeras enzimas importantes para a função microbicida dos macrófagos ${ }^{31}$.

Sabe-se que a respiração desacoplada reduz a formação de ROS advindos da mitocôndria. A explicação para isso é que a formação destas ROS depende do gradiente de prótons e do potencial mitocondrial. Skulahev postulou que ácidos graxos podem prevernir o aumento do gradiente eletroquímico mitocondrial e reduzir a geração de $\operatorname{ROS}^{39}$. Ou seja, a respiração desacoplada exerce uma função antioxidante nas células .

Já foi descrito que ácidos graxos gerados por lipólise são direcionados para a via desacoplada. A via desacoplada também permite uma contínua reoxidação de coenzimas que são essenciais para outras vias metabólicas. Os ácidos graxos são moléculas que quando oxidadas induzem síntese de elevados níveis de ATP, o que pode inibir, através de um feedback negativo, a respiração mitocondrial. Portando, o desacoplamento da síntese de ATP previne o aumento exagerado dos níveis de ATP ${ }^{41}$. 


\subsection{0 fenótipo de monócitos e macrófagos}

Os monócitos são gerados por células precursoras mielóides da medula óssea, e são liberados na corrente sanguínea, de onde eles podem infiltrar nos tecidos, e se diferenciar em macrófagos. Na cavidade peritoneal existem diferentes subtipos de macrófagos com diferentes fenótipos, funções e origens. Na cavidade peritoneal não estimulada, o subtipo de macrófago gerado de células precursoras mielóides da medula óssea predomina. Enquanto em resposta a um estímulo inflamatório, a composição da cavidade peritoneal é alterada. Neste caso, monócitos derivados da medula óssea desaparecem, e macrófagos derivados de monócitos inflamatórios se tornam prevalentes 42. Existem dados da literatura que já reportaram que macrófagos derivados de monócitos com fenótipo inflamatório, se diferenciam em macrófagos com um fenótipo também pró-inflamatório ${ }^{43}$.

Os macrófagos são células que exibem alta plasticidade podendo sofrer reprogramação fenotípica para diferentes subpopulações, identificadas pela predominância de certos marcadores ${ }^{30 ; 44}$. Fleming e Mosser (2011) propuseram uma classificação simplificada dos fenótipos de macrófagos (Fig. 1). Os macrófagos classicamente ativados apresentam expressão de moléculas relacionadas com resposta imune Th1 como Stat1, Nos2, I/12, produção de NO, e são importantes na resposta contra infecções. Os macrófagos reguladores apresentam marcadores pro e anti-inflamatórios com predominância de $/ / 10$ sobre $/ / 12$ e são importantes na regulação negativa da resposta inflamatória. Os macrófagos alternativamente ativados expressam moléculas relacionadas com a resposta Th2 com ativação da STAT6, a qual induz expressão de Arg1, Fizz1 e $Y m 1$, moléculas envolvidas no contexto de reparo tecidual e cicatrização. Em condições de homeostase, a predominância é de marcadores de macrófagos alternativamente ativados. Este perfil também é predominante em processo de cicatrização que exige reparo e remodelamento tecidual $^{45}$. 


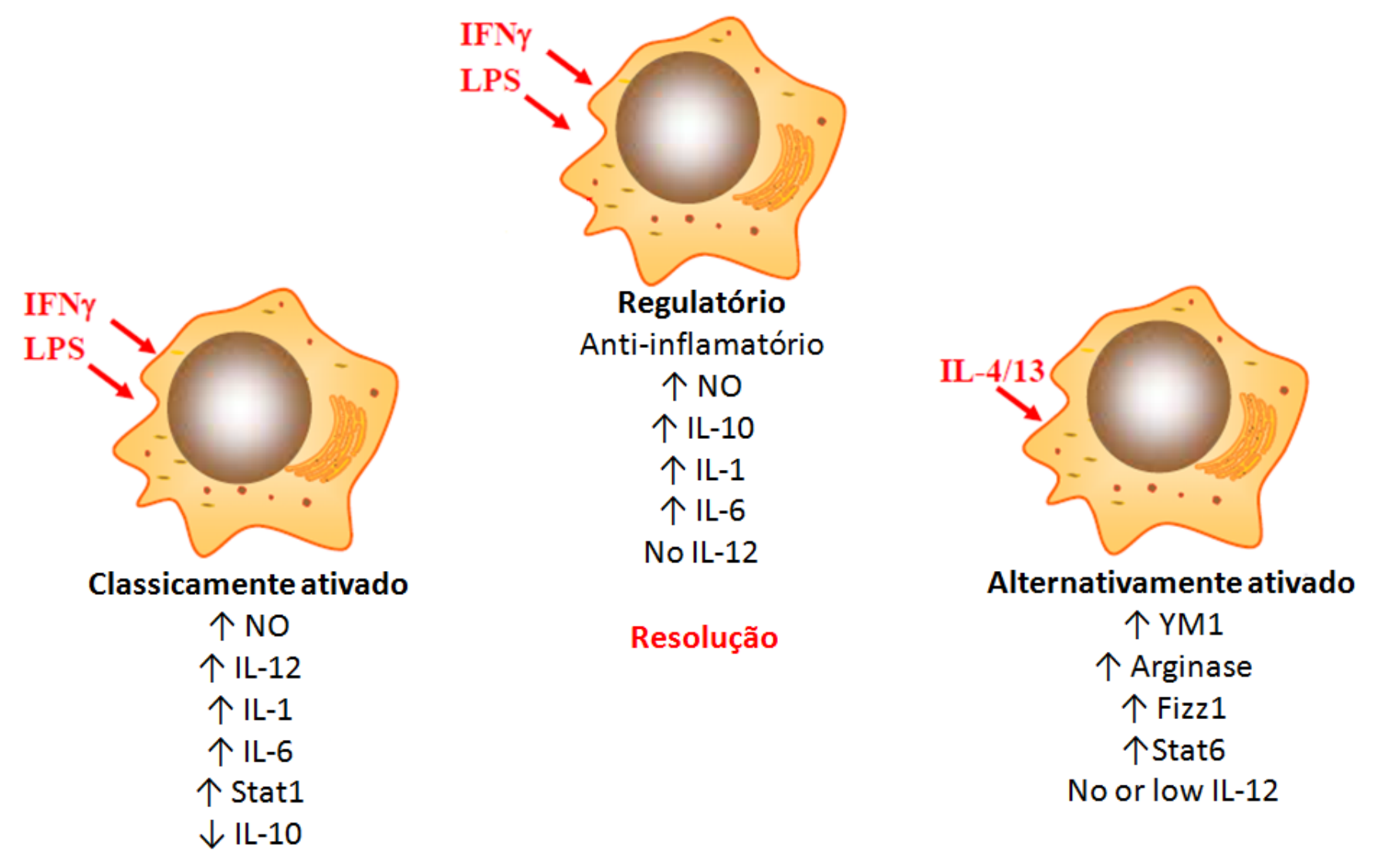

Indução/Manutenção

Reparo/cicatrização

Figura 1. Classificação dos perfis de macrófagos e seus marcadores predominantes. Adaptado de Mosser e Edwards,2012.

Já foi reportado que monócitos isolados de humanos com diabetes tipo 1 exibem uma secreção aumentada de citocinas pro-inflamatórias, como IL-1 $\beta$ e IL-6. Este estudo reportou que estas citocinas induzem o perfil Th17 em linfócitos de memória, um perfil que está diretamente ligado a respostas autoimunes ${ }^{46}$. Em outro estudo, pacientes com diabetes tipo 1 apresentaram elevados níveis de macrófagos M1, e em macrófagos de camundongos diabéticos as células progenitoras da medula óssea apresentam problemas de mobilidade, o que está diretamente relacionado com pacientes que apresentam complicações hematológicas 47

Já os macrófagos isolados de dois modelos diferentes de diabetes tipo $1 \mathrm{em}$ camundongos, exibiram fenótipo inflamatório, o qual está associado com uma expressão aumentada de Acil-CoA sintetase de cadeia longa 1 (ACSL1), uma enzima que cataliza a tiosterificação de ácidos graxos. Neste estudo, macrófagos residentes, ou 
elicitados apresentam uma alta expressão de moléculas associadas com o fenótipo proinflamatório, como Il1b, Tnfa e Cox2. E a deficiência de ACSL1 nos macrófagos reduz os níveis de araquidonoil - CoA e a secreção do mediador lipídico prostaglandina E2 (PGE2) em condições de hiperglicemia in vitro. Neste estudo, o perfil inflamatório atrelado com ACSL1 está fortemente relacionado com o desenvolvimento de aterosclerose no DT1 ${ }^{6}$.

\subsection{Os leucotrienos}

Os leucotrienos são mediadores lipídicos gerados a partir do metabolismo do ácido araquidônico (AA) pela enzima 5-lipoxigenase (5-LO). O AA esterificado é liberado da membrana celular através da clivagem pela fosfolipase (PL) A2. As células mielóides expressam de forma constitutiva tanto a PLA2 como as demais enzimas da via da 5-LO, e geram quantidades elevadas de LTs em poucos minutos após um estimulo $^{48}$. Para que esta síntese de leucotrienos ocorra, a 5-LO e a PLA2 precisam ser ativadas, o que pode ocorrer por aumento de cálcio intracelular. Juntamente com a proteína acessória FLAP (5-lipoxygenase-activating protein), a 5-LO oxida o AA gerando o intermediário LTA4, que é rapidamente hidrolisado pela LTA4 hidrolase gerando o LTB4. Se ao invés de hidrolisado, o LTA4 for conjugado com a forma reduzida da glutationa pela LTC4 sintase, origina-se o LTC4, um LT da família dos cisteinil leucotrienos (cysLTs), como o LTD4 e o LTE4 (Fig. 2). Cada célula possui seu próprio perfil de produção de LTs, e essa especificidade é dada pelo balanço na expressão destas enzimas. Enquanto mastócitos e eosinófilos sintetizam preferencialmente os cysLTs, e os neutrófilose e células dendríticas preferencialmente o LTB4, os macrófagos tem capacidade de produzir ambos ${ }^{49}$. 


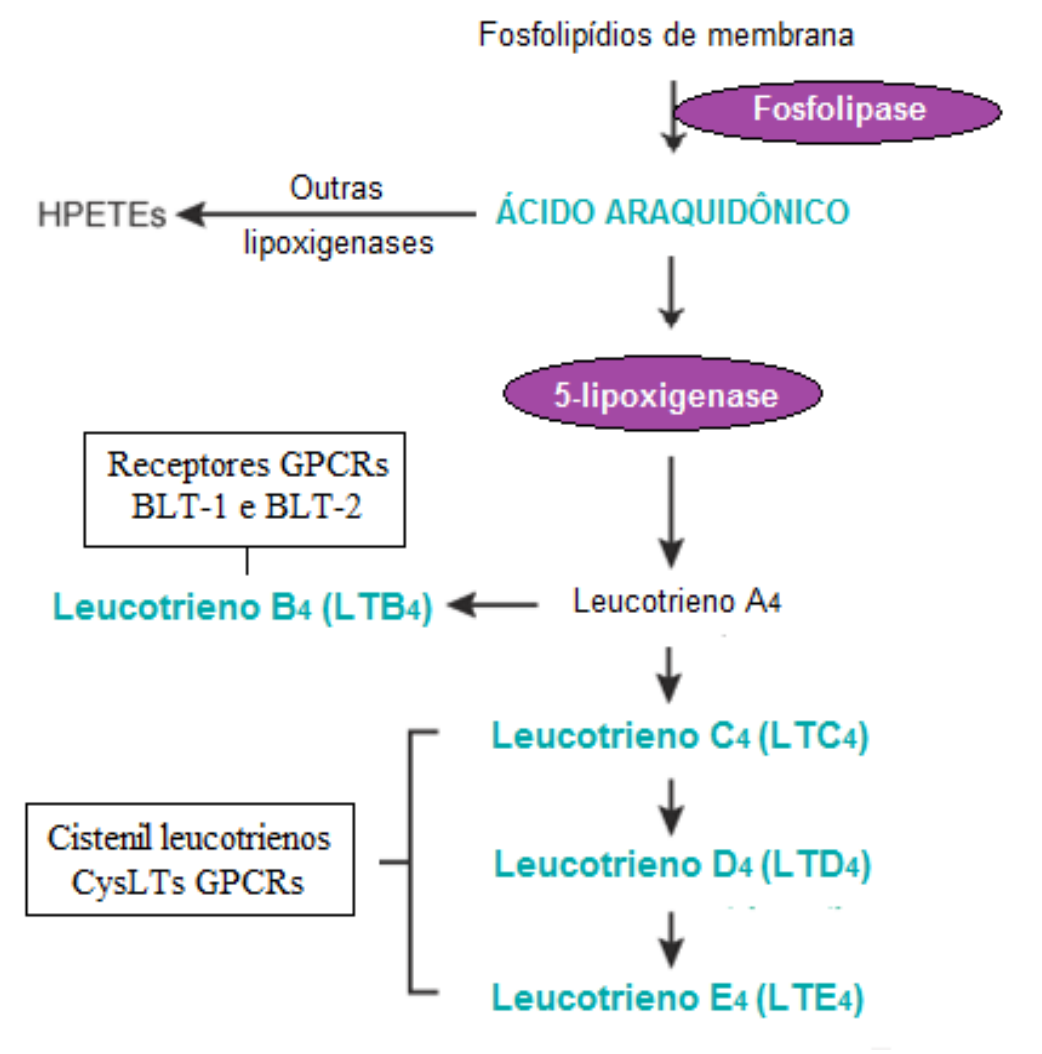

Figura 2. Esquema representativo do metabolismo do ácido araquidônico via 5LO. A ativação da fosfolipase A2 (PLA2) cliva fosfolipídios de membrana liberando o ácido araquidônico (AA) o qual sofre ação da 5-lipoxigenase (5LO) para produzir 5-HPETE. Este é então metabolizado em leucotrieno A4 (LTA4), metabólito instável que dá origem ao leucotrieno B4, pela ação da LTA4 hidrolase. Pela ação da LTC4 sintase que incorpora glutationa na molécula de LTA4, são gerados os cistenil leucotrienos LTC4, LTE4 e LTD4.

Através de seus receptores acoplados a proteína G, os LTs regulam a função de diversos tipos celulares de forma autócrina ou parácrina. Existem dois receptores em que o LTB4 liga, o BLT1 e o BLT2. Enquanto o BLT2 é um receptor de baixa afinidade, e pouco se sabe sobre suas funções fisiológicas, o BLT1 é um receptor de alta afinidade por LTB4. Este receptor pode ser acoplado tanto proteína Gai, como Gaq. Via proteína Gai,o LTB4 inibe a atividade da adenilato ciclase, levando a diminuição dos níveis intracelulares de monofosfato cíclico de adenosina (AMPc). Já através do acoplamento com a proteina Gaq, ocorre ativação da PLC $\beta$, que induz o acumulo de IP3 (1,4,5 trifosfato de inositol), e ativação da proteína quinase C (PKC). Através destas duas enzimas, o LTB4 potencializa as funções fagocíticas, microbicidas e de produção 
de citocinas ${ }^{50}$. Foi demonstrado que via proteína Gai, o LTB4 ativa macrófagos pelos TLRs que utilizam MyD88 como molécula adaptadora. Serezani e colaboradores, 2011, mostraram que a ativação do BLT1 pelo LTB4 aumenta a degradação do RNAm de SOCS1, uma proteína inibidora que controla a expressão de MyD88 através da inibição do seu fator de transcrição, o STAT1 ${ }^{51}$. Isto potencializa a resposta de receptores que utilizam Myd88 como adaptador como os receptores toll-like e receptores para citocinas IL-1, IL-18 e IL-33.

Portanto o LTB4 funciona como um amplificador da resposta inflamatória. Esta molécula possui atividade quimiotática para leucócitos e potencializa suas funções como fagocitose, atividade microbicida e produção de citocinas. Recentemente diversos trabalhos demonstraram a participação do LTB4 em desordens metabólicas. Em modelo experimental de gota, induzido pela inoculação de cristais de urato na articulação de camundongos, foi demonstrado que a LGI é dependente do LTB4 que é rapidamente produzido logo após a inoculação ${ }^{52}$. Já em camundongos com diabetes tipo 2 induzida por dieta hiperlipídica, observa-se uma produção aumentada de LTB4 no fígado, músculo e no tecido adiposo. No tecido adiposo, o LTB4 promove o recrutamento de macrófagos e a polarização destes para um perfil classicamente ativado (M1) que passam a produzir citocinas e mediadores pró-inflamatórios. No fígado e no tecido muscular, o LTB4 afeta o metabolismo da glicose. A ativação do BLT1 em hepatócitos induz a resistência a insulina por inibir a expressão de componentes da via de sinalização do receptor de insulina. Nas células musculares, a ativação do BLT1 promove resistência a insulina de forma similar ao que acontece nos hepatócitos. Estes estudos sugerem que o LTB4 produzido no diabetes tipo 2 contribui para a manutenção da hiperglicemia e da inflamação estéril. Tanto a inibição genética ou farmacológica do BLT1 como o bloqueio da síntese de LTB4 se mostraram eficientes como tratamento do diabetes tipo 2 indicando um papel central do LTB4 nesta doença ${ }^{53 ; 54}$.

Já no diabetes tipo 1, nosso grupo demonstrou que macrófagos (peritoneais, alveolares e derivados de medula) de animais diabéticos expressam níveis aumentados de MyD88 e que isto acontece devido a produção de LTB4 que está aumentada nos diabéticos. Vimos ainda que a produção sistêmica de IL-1 $\beta$ e TNF- $\alpha$, é dependente da produção de LTB4, pois animais diabéticos tratados com inibidor de 5LO ou animais geneticamente deficientes de 5LO e BLT1 apresentam níveis significativamente reduzidos dessas citocinas ${ }^{7}$. Dessa maneira, o LTB4 poderia contribuir para a LGI dos diabéticos. Além disso, os macrófagos de camundongos com diabetes tipo 1 apresentam 
um fenótipo M1 que se caracteriza por produção elevada de citocinas pró-inflamatórias, contrastando com macrófagos de animais não-diabéticos que exibem fenótipo antiinflamatório ${ }^{55}$.

\subsection{A cicatrização saudável e a patológica}

Os macrófagos têm um papel importante em processos de reparo tecidual de lesões da pele, através da expressão de marcadores de macrófagos alternativamente ativados, os quais promovem angiogenese, deposição de colágeno e fechamento da lesão ${ }^{56}$. De forma geral, o processo de cicatrização se procede em 3 fases, como descrito a seguir.

A fase de coagulação e inflamação começa imediatamente após a injúria e pode durar até 4 dias, dependendo do tamanho e local da lesão. Nesta fase, a injúria tecidual leva a ativação da cascata de coagulação. O sangue coagulado forma uma matriz provisória no seu redor que induz a liberação local de fatores de crescimento, bem como citocinas pro-inflamatórias e DAMPs ${ }^{57}$. Nesta fase, os macrófagos residentes de tecido contribuem para o início de uma resposta inflamatória local, que também leva ao influxo de neutrófilos, seguido de monócitos e fibroblastos para a lesão ${ }^{58}$. Os monócitos infiltram a lesão através das micro-hemorragias causadas pelo rompimento da integridade vascular local ${ }^{59}$. O influxo de monócitos leva os macrófagos a expressarem iNOS, IL-1 $\beta$ e IL-6. Isso contribui para a defesa contra microorganismos que podem ter entrado na lesão ${ }^{60}$. Sabe-se que estas células combatem microorganismos, porém também se sabe que elas suportam o processo de reparo que inicia a fase de formação tecidual.

Esta fase de formação tecidual dura até cinco dias contados após o início da fase de coagulação e inflamação. Durante esta fase, o tecido granulado recém-formado que consiste de células endoteliais, macrófagos e fibroblastos, recobre e preenche a área lesionada. Queratinócitos também proliferam e migram das margens da lesão em direção ao centro da abertura da lesão, o que fecha a lacuna epidermal ${ }^{58}$. Macrófagos são as células imunes mais incidentes durante a fase de formação tecidual, pois eles contribuem para secreção de fatores de crescimento, deposição de matriz extracelular e controle da inflamação ${ }^{56}$. O primeiro passo que inicia o controle da inflamação é a ingestão de neutrófilos apoptóticos pelos macrófagos 61;62. Uma molécula que é bastante secretada pelos macrófagos nesta fase é a YM1. Esta molécula é membro de 
uma família que proteínas de mamíferos que compartilham homologia com quitinases de organismos inferiores ${ }^{63}$. Ela é produzida quando os macrófagos estão em um microambiente de citocinas Th2. Devido à sua função primária de forte afinidade com quitina, define-se que YM1 esteja envolvido na neutralização de patógenos e recrutamento de células imunes. Esta molécula também tem alta afinidade com heparin, um glicano bastante presente na matriz extracelular, por isso propõe-se que $Y m 1$ tenha uma função essencial no processo de cicatrização ${ }^{64}$. A arginase é outra molécula derivada de macrófagos que exerce atividade no reparo tecidual devido à sua atividade da supressão da inflamação. A arginase converte arginina em ornitina, que serve como um precursor de moléculas constituintes de colágeno. Arginase também suprime a resposta inflamatória pois arginase compete com iNOS pelo mesmo substrato, a arginina ${ }^{65}$.

Uma vez que a inflamação local está controlada, inicia-se a última fase do processo de cicatrização que é o remodelamento tecidual. Nesta fase a organização tecidual retorna à sua forma original. Esta fase pode durar semanas ou meses, e os fatores mais atuantes são células endoteliais residentes, macrófagos e miofibroblastos (em apoptose), regressão de vasos sanguíneos recém formados, e reorganização de camadas de colágeno recém formadas. Durante esta fase, os macrófagos contribuem para a cicatrização através da ingestão de debris celulares e do excesso de matriz extracelular ao redor da lesão. Porém, a depleção de macrófagos da lesão nesta fase não apresenta um impacto substancial no remodelamento, o que sugere que os macrófagos são parte de um sistema redundante na fase de reorganização tecidual ${ }^{56 ; 66}$.

Os problemas de cicatrização em pacientes diabéticos são um desafio recorrente na prática clínica, com constantes resultados frustrantes, mesmo o paciente prestando todas as condutas que evitem uma má cicatrização. Estas lesões dificultam a qualidade de vida de milhões de pacientes diabéticos ${ }^{67}$.

Em situações patológicas como no diabetes tipo 1, é possível que a fase de resolução da inflamação seja retardada ou não aconteça, comprometendo a fase seguinte de cicatrização. A predominância de macrófagos pro-inflamatórios sobre os antiinflamatórios, com produção aumentada de citocinas pró-inflamatórias, desabilita o mecanismo de reparo ${ }^{68}$. No caso de injuria da medula espinal foi relatado que o TNF- $\alpha$, bloqueia a conversão de macrófagos inflamatórios (classicamente ativados) para fenótipo reparador (alternativamente ativado) ${ }^{69}$. A abundância de citocinas proinflamatórias também aumenta a degradação da matriz extracelular, dificulta a migração 
celular, reduz a proliferação de fibroblastos e a síntese de colágeno ${ }^{70}$. Assim é possível que nos diabéticos os leucotrienos interfiram nesta alternância de fenótipos. Também existem evidências de que a hiperglicemia leva a mudanças no perfil de microRNAs na cicatrização. Por exemplo, o mir125b aumenta a responsividade de macrófagos da lesão a IFN $\gamma$, e isso inibe o fenótipo reparativo, pois o miR125b tem como alvo o fator de transcrição IRF4, relacionado com o perfil de macrófago alternativamente ativado ${ }^{71}$. Já a dislipidemia, um sintoma clássico de pacientes diabeticos, também tem sido associada com problemas de cicatrização, pois o excesso de lipídios na lesão induz metilação no DNA que reprime citocinas anti-inflamatórias ${ }^{72}$.

\subsection{Modelo de diabetes tipo 1 induzido por estreptozotocina}

A estreptozotocina [STZ, 2-deoxy-2-(3-(methyl-3-nitrosoureido)-Dglucopyranose)] (STZ) é um derivado de nitrosoureia que foi inicialmente isolada da fermentação do fungo Streptomycetes achromogenes Sua estrutura molecular foi inicialmente descrita por Herr et al em $1967^{73}$, e corresponde a um 2-deoxy-D-glucose com adição de um grupo N-methyl-N-nitroseurea no $\mathrm{C}_{2}$.

O STZ é membro de um grupo de drogas alquilantes antineoplásicas, conhecidas por alquilnitrosoureas que são clinicamente ativas contra vários tipos de tumores e em combinação com outros quimioterápicos ${ }^{74}$. Além disso, esta molécula é classicamente utilizada para indução de diabetes tipo 1 (dependente de insulina) em animais experimentais através dos seus efeitos nas células $\beta$ do pâncreas.

O STZ pode ser captado pelas células pancreáticas via GLUT2, um transportador de glicose. Wang and Gleichmann ${ }^{75}$ reportaram que STZ reduz a expressão de GLUT2 in vivo e in vitro quando administrado em múltiplas doses. A ação intracelular do STZ é a fragmentação do DNA por alquilação, o que gera diferentes purinas metiladas como produto. Nesta reação, o NO advindo do STZ interage com o DNA, danificando-o. Isso independe da ação da NO sintase ${ }^{76}$. As EROS, como ànions superóxidos também participam do dano no DNA. Este dano ativa a poli ADPribosilação, que depleta $\mathrm{NAD+}$, levando a redução dos níveis de ATP intracelular, e consequente inibição da síntese e secreção de insulina ${ }^{77}$. Os danos nas células $\beta$ pancreáticas geram então um estado de estresse celular que ocasiona na ativação de moléculas intracelulares, como a maquinaria do inflamassoma, que induz apoptose. 
Uma vez montada esta maquinaria, o dano celular é irreversível, o que leva a um estado sistêmico e crônico de hiperglicemia ${ }^{78}$.

Neste trabalho utilizamos a STZ para indução de diabetes tipo 1 em camundongos, seguindo um protocolo de multiplas doses, como descrito na seção de Material e Métodos. O modelo de diabetes tipo 1 induzido por STZ simula fortemente a hiperglicemia e as consequentes complicações de pacientes diabéticos, como perda de peso, hiperlipidemia e inflamação sistêmica.

Pelo exposto nesta seção, vimos que o LTB4 contribui para o desenvolvimento da LGI no diabetes e a reprogramação dos macrófagos para um perfil pro-inflamatório. Entretanto não se sabe se o LTB4 está envolvido nas mudanças metabólicas, na perda de adiposidade, e na cicatrização deficiente no diabetes. Foi objetivo do presente estudo responder estas questões em modelo experimental de diabetes induzido por estreptozotocina. Para isto, na primeira parte do trabalho investigamos o papel do LTB4 no metabolismo lipídico sistêmico e de macrófagos. E na segunda parte, investigamos o papel dos leucotrienos no fenótipo de monócitos e macrófagos e no retardo da cicatrização de camundongos com diabetes tipo 1 . 


\section{CONCLUSÃO}

Nossos dados indicam que no diabetes tipo 1, o LTB4 tem envolvimento em perda de adiposidade, aumento da hiperlipidemia sistêmica, redução da síntese e aumento da captação de lipídios em macrófagos, e aumento do metabolismo energético de macrófagos.

Já os leucotrienos no diabetes tipo 1 estão envolvidos com amplificação da inflamação sistêmica, perfil pró-inflamatório de monócitos circulantes, perfil de macrófagos classicamente ativados, restrição de ativação alternativa dessas células, e atraso do processo de cicatrização. Baseado nos antigos relatos do nosso grupo, e de acordo com esta parte do trabalho em que encontramos elevados níveis de LTB4 no sangue dos camundongos diabéticos, sugerimos que dentre os leucotrienos, o LTB4 seja o principal candidato a exercer efeitos sobre inflamação, macrófagos e cicatrização.

Portanto, juntos nossos dados indicam que o LTB4 possua um papel relevante no elo entre metabolismo e inflamação, o que modula o perfil funcional e metabólico de macrófagos residentes, e leva a um consequente retardo no processo de cicatrização. 



\section{REFERÊNCIAS}

DANEMAN, D. Type 1 diabetes. Lancet, v. 367, n. 9513, p. 847-58, Mar 2006. ISSN 1474-547X. Disponível em: < https://www.ncbi.nlm.nih.gov/pubmed/16530579 >.

PASCHOU, S. A. et al. Type 1 diabetes as an autoimmune disease: the evidence. Diabetologia, v. 57, n. 7, p. 1500-1, Jul 2014. ISSN 1432-0428. Disponível em: < https://www.ncbi.nlm.nih.gov/pubmed/24705607 >.

OGURTSOVA, K. et al. IDF Diabetes Atlas: Global estimates for the prevalence of diabetes for 2015 and 2040. Diabetes Res Clin Pract, v. 128, p. 40-50, Jun 2017. ISSN 1872-8227. Disponível em: < https://www.ncbi.nlm.nih.gov/pubmed/28437734 >.

ROSENFALCK, A. M. et al. Body composition in adults with Type 1 diabetes at onset and during the first year of insulin therapy. Diabet Med, v. 19, n. 5, p. 417-23, May 2002. ISSN 0742-3071. Disponível em: < https://www.ncbi.nlm.nih.gov/pubmed/12027931 >.

WILLECKE, F. et al. Lipolysis, and not hepatic lipogenesis, is the primary modulator of triglyceride levels in streptozotocin-induced diabetic mice. Arterioscler Thromb Vasc Biol, v. 35, n. 1, p. 102-10, Jan 2015. ISSN 1524-4636. Disponível em: < https://www.ncbi.nlm.nih.gov/pubmed/25395613 >.

KANTER, J. E. et al. Diabetes promotes an inflammatory macrophage phenotype and atherosclerosis through acyl-CoA synthetase 1. Proc Natl Acad Sci U S A, v. 109, n. 12, p. E715-24, Mar 2012. ISSN 1091-6490. Disponível em: < https://www.ncbi.nlm.nih.gov/pubmed/22308341 >.

FILGUEIRAS, L. R. et al. Leukotriene B4-mediated sterile inflammation promotes susceptibility to sepsis in a mouse model of type 1 diabetes. Sci Signal, v. 8, n. 361, p. ra10, Jan 2015. ISSN 1937-9145. Disponível em: < https://www.ncbi.nlm.nih.gov/pubmed/25628460 >

REMMERIE, A.; SCOTT, C. L. Macrophages and lipid metabolism. Cell Immunol, Feb 2018. ISSN 1090-2163. Disponível em: < https://www.ncbi.nlm.nih.gov/pubmed/29429624 >. 289, n. 35, p. 24020-9, Aug 2014. ISSN 1083-351X. Disponível em: < https://www.ncbi.nlm.nih.gov/pubmed/25074931 >. 

2001. ISSN 1262-3636. Disponível em: < https://www.ncbi.nlm.nih.gov/pubmed/11452214 >.

MALMSTRÖM, R. et al. Effects of insulin and acipimox on VLDL1 and VLDL2 apolipoprotein B production in normal subjects. Diabetes, v. 47, n. 5, p. 779-87, May 1998. ISSN 0012-1797. Disponível em: < https://www.ncbi.nlm.nih.gov/pubmed/9588450 >.

BRUNZELL, J. D. et al. Insulin and adipose tissue lipoprotein lipase activity in humans. Int J Obes, v. 5, n. 6, p. 685-94, 1981. Disponível em: < https://www.ncbi.nlm.nih.gov/pubmed/7033152 >.

WEIDMAN, S. W. et al. Effects of insulin on plasma lipoproteins in diabetic ketoacidosis: evidence for a change in high density lipoprotein composition during treatment. J Lipid Res, v. 23, n. 1, p. 171-82, Jan 1982. ISSN 0022-2275. Disponível em: < https://www.ncbi.nlm.nih.gov/pubmed/6799600 >

MARCOVECCHIO, M. L. et al. Prevalence of abnormal lipid profiles and the relationship with the development of microalbuminuria in adolescents with type 1 diabetes. Diabetes Care, v. 32, n. 4, p. 658-63, Apr 2009. ISSN 1935-5548. Disponível em: < https://www.ncbi.nlm.nih.gov/pubmed/19171721 >.

GUY, J. et al. Lipid and lipoprotein profiles in youth with and without type 1 diabetes: the SEARCH for Diabetes in Youth case-control study. Diabetes Care, v. 32, n. 3, p. 41620, Mar 2009. ISSN 1935-5548. Disponível em: < https://www.ncbi.nlm.nih.gov/pubmed/19092167 >.

DULLAART, R. P. et al. Increased cholesterylester transfer activity in complicated type 1 (insulin-dependent) diabetes mellitus--its relationship with serum lipids.

Diabetologia, v. 32, n. 1, p. 14-9, Jan 1989. ISSN 0012-186X. Disponível em: < https://www.ncbi.nlm.nih.gov/pubmed/2707515 >.

RITCHIE, R. H. et al. Lipid metabolism and its implications for type 1 diabetesassociated cardiomyopathy. J Mol Endocrinol, v. 58, n. 4, p. R225-R240, May 2017. ISSN 1479-6813. Disponível em: < https://www.ncbi.nlm.nih.gov/pubmed/28373293 >.

HEBERT, S. L.; NAIR, K. S. Protein and energy metabolism in type 1 diabetes. Clin Nutr, v. 29, n. 1, p. 13-7, Feb 2010. ISSN 1532-1983. Disponível em: < https://www.ncbi.nlm.nih.gov/pubmed/19788950 >.

KAHRI, J. et al. Regulation of apolipoprotein A-I-containing lipoproteins in IDDM. Diabetes, v. 42, n. 9, p. 1281-8, Sep 1993. ISSN 0012-1797. Disponível em: < https://www.ncbi.nlm.nih.gov/pubmed/8349039 >. 

uncoupling in brown fat mitochondria. Cell, v. 151, n. 2, p. 400-13, Oct 2012. ISSN 1097-4172. Disponível em: < https://www.ncbi.nlm.nih.gov/pubmed/23063128 >.

ARRUDA, A. P. et al. Hypothalamic actions of tumor necrosis factor alpha provide the thermogenic core for the wastage syndrome in cachexia. Endocrinology, v. 151, n. 2, p. 683-94, Feb 2010. ISSN 1945-7170. Disponível em: < https://www.ncbi.nlm.nih.gov/pubmed/19996183 >.

RUAN, $\mathrm{H}$. et al. Tumor necrosis factor-alpha suppresses adipocyte-specific genes and activates expression of preadipocyte genes in 3T3-L1 adipocytes: nuclear factorkappaB activation by TNF-alpha is obligatory. Diabetes, v. 51, n. 5, p. 1319-36, May 2002. ISSN 0012-1797. Disponível em: < https://www.ncbi.nlm.nih.gov/pubmed/11978627 >.

NAIR, K. S.; HALLIDAY, D.; GARROW, J. S. Increased energy expenditure in poorly controlled Type 1 (insulin-dependent) diabetic patients. Diabetologia, v. 27, n. 1, p. 136, Jul 1984. ISSN 0012-186X. Disponível em: < https://www.ncbi.nlm.nih.gov/pubmed/6147290 $>$.

NAIR, K. S. Hyperglucagonemia increases resting metabolic rate in man during insulin deficiency. J Clin Endocrinol Metab, v. 64, n. 5, p. 896-901, May 1987. ISSN 0021-972X. Disponível em: < https://www.ncbi.nlm.nih.gov/pubmed/2881943 $>$.

CHHIBBER, V. L.; SORIANO, C.; TAYEK, J. A. Effects of low-dose and high-dose glucagon on glucose production and gluconeogenesis in humans. Metabolism, v. 49, n. 1, p. 3946, Jan 2000. ISSN 0026-0495. Disponível em: < https://www.ncbi.nlm.nih.gov/pubmed/10647062 >. fat deposition. Mediators Inflamm, v. 2014, p. 418185, 2014. ISSN 1466-1861. Disponível em: < https://www.ncbi.nlm.nih.gov/pubmed/25143667 >.

ELENKOV, I. J. et al. Cytokine dysregulation, inflammation and well-being. Neuroimmunomodulation, v. 12, n. 5, p. 255-69, 2005. ISSN 1021-7401. Disponível em: $<$ https://www.ncbi.nlm.nih.gov/pubmed/16166805 $>$. associated with altered blood lipid levels. Atherosclerosis, v. 263, p. 15-23, Aug 2017. ISSN 1879-1484. Disponível em: < https://www.ncbi.nlm.nih.gov/pubmed/28570862 >. the American Heart Association. Circulation, v. 123, n. 20, p. 2292-333, May 2011. ISSN 1524-4539. Disponível em: < https://www.ncbi.nlm.nih.gov/pubmed/21502576 >. 

v. 6, p. 637, 2015. ISSN 1664-3224. Disponível em: < https://www.ncbi.nlm.nih.gov/pubmed/26779183 >. immunologists. Nat Rev Immunol, v. 16, n. 9, p. 553-65, 09 2016. ISSN 1474-1741. Disponível em: < https://www.ncbi.nlm.nih.gov/pubmed/27396447 >. obesity-induced insulin resistance. J Biol Chem, v. 282, n. 42, p. 30794-803, Oct 2007. ISSN 0021-9258. Disponível em: < https://www.ncbi.nlm.nih.gov/pubmed/17724031 >.

HUTCHINS, P. M.; HEINECKE, J. W. Cholesterol efflux capacity, macrophage reverse cholesterol transport and cardioprotective HDL. Curr Opin Lipidol, v. 26, n. 5, p. 38893, Oct 2015. ISSN 1473-6535. Disponível em: < https://www.ncbi.nlm.nih.gov/pubmed/26270810 >.

HUANG, S. C. et al. Cell-intrinsic lysosomal lipolysis is essential for alternative activation of macrophages. Nat Immunol, v. 15, n. 9, p. 846-55, Sep 2014. ISSN 15292916. Disponível em: < https://www.ncbi.nlm.nih.gov/pubmed/25086775 >.

MEHTA, M. M.; WEINBERG, S. E.; CHANDEL, N. S. Mitochondrial control of immunity: beyond ATP. Nat Rev Immunol, v. 17, n. 10, p. 608-620, Oct 2017. ISSN 1474-1741. Disponível em: < https://www.ncbi.nlm.nih.gov/pubmed/28669986 >. Acta, v. 1757, n. 5-6, p. 459-66, 2006 May-Jun 2006. ISSN 0006-3002. Disponível em: < https://www.ncbi.nlm.nih.gov/pubmed/16725104 >.

O'NEILL, L. A.; PEARCE, E. J. Immunometabolism governs dendritic cell and macrophage function. J Exp Med, v. 213, n. 1, p. 15-23, Jan 2016. ISSN 1540-9538. Disponível em: < https://www.ncbi.nlm.nih.gov/pubmed/26694970 $>$.

RAHA, S.; ROBINSON, B. H. Mitochondria, oxygen free radicals, disease and ageing. Trends Biochem Sci, v. 25, n. 10, p. 502-8, Oct 2000. ISSN 0968-0004. Disponível em: < https://www.ncbi.nlm.nih.gov/pubmed/11050436 >.

SKULACHEV, V. P. Uncoupling: new approaches to an old problem of bioenergetics. Biochim Biophys Acta, v. 1363, n. 2, p. 100-24, Feb 1998. ISSN 0006-3002. Disponível em: <https://www.ncbi.nlm.nih.gov/pubmed/9507078 >. 

species--or not? Biochim Biophys Acta, v. 1757, n. 5-6, p. 449-58, 2006 May-Jun 2006. ISSN 0006-3002. Disponível em: < https://www.ncbi.nlm.nih.gov/pubmed/16806053 >. Suppl 1, p. S130-5, Feb 2004. ISSN 0012-1797. Disponível em: < https://www.ncbi.nlm.nih.gov/pubmed/14749278 >. peritoneal macrophages: heterogeneity, development, and function. Front Immunol, v. 6 , p. 225, 2015. ISSN 1664-3224. Disponível em: < https://www.ncbi.nlm.nih.gov/pubmed/26042120 >.

GHANIM, $\mathrm{H}$. et al. Circulating mononuclear cells in the obese are in a proinflammatory state. Circulation, v. 110, n. 12, p. 1564-71, Sep 2004. ISSN 1524-4539. Disponível em: < https://www.ncbi.nlm.nih.gov/pubmed/15364812 >.

GORDON, S.; TAYLOR, P. R. Monocyte and macrophage heterogeneity. Nat Rev Immunol, v. 5, n. 12, p. 953-64, Dec 2005. ISSN 1474-1733. Disponível em: < http://www.ncbi.nlm.nih.gov/pubmed/16322748 >.

MURRAY, P. J. et al. Macrophage activation and polarization: nomenclature and experimental guidelines. Immunity, v. 41, n. 1, p. 14-20, Jul 2014. ISSN 1097-4180. Disponível em: <http://www.ncbi.nlm.nih.gov/pubmed/25035950 $>$.

BRADSHAW, E. M. et al. Monocytes from patients with type 1 diabetes spontaneously secrete proinflammatory cytokines inducing Th17 cells. J Immunol, v. 183, n. 7, p. 4432-9, Oct 2009. ISSN 1550-6606. Disponível em: < https://www.ncbi.nlm.nih.gov/pubmed/19748982 >.

ALBIERO, M. et al. Bone Marrow Macrophages Contribute to Diabetic Stem Cell Mobilopathy by Producing Oncostatin M. Diabetes, v. 64, n. 8, p. 2957-68, Aug 2015. ISSN 1939-327X. Disponível em: < https://www.ncbi.nlm.nih.gov/pubmed/25804939 >.

PETERS-GOLDEN, M.; HENDERSON, W. R. Leukotrienes. N Engl J Med, v. 357, n. 18, p. 1841-54, Nov 2007. ISSN 1533-4406. Disponível em: < https://www.ncbi.nlm.nih.gov/pubmed/17978293 >.

PETERS-GOLDEN, $M$. et al. Leukotrienes: underappreciated mediators of innate immune responses. J Immunol, v. 174, n. 2, p. 589-94, Jan 2005. ISSN 0022-1767. Disponível em: < https://www.ncbi.nlm.nih.gov/pubmed/15634873 $>$.

PERES, C. M. et al. Specific leukotriene receptors couple to distinct $G$ proteins to effect stimulation of alveolar macrophage host defense functions. J Immunol, v. 179, n. 8, p. 
5454-61, Oct 2007. ISSN 0022-1767. Disponível em: < https://www.ncbi.nlm.nih.gov/pubmed/17911632 >. macrophages by reducing SOCS1 inhibition of MyD88 expression. J Clin Invest, v. 121, n. 2, p. 671-82, Feb 2011. ISSN 1558-8238. Disponível em: < http://www.ncbi.nlm.nih.gov/pubmed/21206089 >.

AMARAL, F. A. et al. NLRP3 inflammasome-mediated neutrophil recruitment and hypernociception depend on leukotriene $B(4)$ in a murine model of gout. Arthritis Rheum, v. 64, n. 2, p. 474-84, Feb 2012. ISSN 1529-0131. Disponível em: < https://www.ncbi.nlm.nih.gov/pubmed/21952942 >. systemic insulin resistance in diet-induced obesity. J Immunol, v. 187, n. 4, p. 1942-9, Aug 2011. ISSN 1550-6606. Disponível em: < https://www.ncbi.nlm.nih.gov/pubmed/21742977 >.

LI, P. et al. LTB4 promotes insulin resistance in obese mice by acting on macrophages, hepatocytes and myocytes. Nat Med, v. 21, n. 3, p. 239-47, Mar 2015. ISSN 1546-170X. Disponível em: < https://www.ncbi.nlm.nih.gov/pubmed/25706874 >.

BAUMANN, B.; SALEM, H. H.; BOEHM, B. O. Anti-inflammatory therapy in type 1 diabetes. Curr Diab Rep, v. 12, n. 5, p. 499-509, Oct 2012. ISSN 1539-0829. Disponível em: < https://www.ncbi.nlm.nih.gov/pubmed/22791179 $>$.

LUCAS, T. et al. Differential roles of macrophages in diverse phases of skin repair. J Immunol, v. 184, n. 7, p. 3964-77, Apr 2010. ISSN 1550-6606. Disponível em: < https://www.ncbi.nlm.nih.gov/pubmed/20176743 >.

DUTRA, F. F.; BOZZA, M. T. Heme on innate immunity and inflammation. Front Pharmacol, v. 5, p. 115, 2014. ISSN 1663-9812. Disponível em: < https://www.ncbi.nlm.nih.gov/pubmed/24904418 >.

MINUTTI, C. M. et al. Tissue-specific contribution of macrophages to wound healing. Semin Cell Dev Biol, v. 61, p. 3-11, 01 2017. ISSN 1096-3634. Disponível em: < https://www.ncbi.nlm.nih.gov/pubmed/27521521 >. into mouse skin wounds. PLoS One, v. 9, n. 10, p. e108212, 2014. ISSN 1932-6203. Disponível em: < https://www.ncbi.nlm.nih.gov/pubmed/25272047 >. 

critical for angiogenesis in tissue repair. Blood, v. 120, n. 3, p. 613-25, Jul 2012. ISSN 1528-0020. Disponível em: < https://www.ncbi.nlm.nih.gov/pubmed/22577176 >.

ZHAO, Y. et al. Thrombospondin-1 triggers macrophage IL-10 production and promotes resolution of experimental lung injury. Mucosal Immunol, v. 7, n. 2, p. 4408, Mar 2014. ISSN 1935-3456. Disponível em: < https://www.ncbi.nlm.nih.gov/pubmed/24045574 >.

OUYANG, W. et al. Regulation and functions of the IL-10 family of cytokines in inflammation and disease. Annu Rev Immunol, v. 29, p. 71-109, 2011. ISSN 15453278. Disponível em: < https://www.ncbi.nlm.nih.gov/pubmed/21166540 $>$.

$\mathrm{JIN}, \mathrm{H}$. M. et al. Genetic characterization of the murine $\mathrm{Ym} 1$ gene and identification of a cluster of highly homologous genes. Genomics, v. 54, n. 2, p. 316-22, Dec 1998. ISSN 0888-7543. Disponível em: < https://www.ncbi.nlm.nih.gov/pubmed/9828134 >.

CHANG, N. C. et al. A macrophage protein, Ym1, transiently expressed during inflammation is a novel mammalian lectin. J Biol Chem, v. 276, n. 20, p. 17497-506, May 2001. ISSN 0021-9258. Disponível em: < https://www.ncbi.nlm.nih.gov/pubmed/11297523 >.

$\mathrm{CHOI}, \mathrm{B}$. S. et al. Differential impact of L-arginine deprivation on the activation and effector functions of T cells and macrophages. J Leukoc Biol, v. 85, n. 2, p. 268-77, Feb 2009. ISSN 0741-5400. Disponível em:< https://www.ncbi.nlm.nih.gov/pubmed/19008294 >. GURTNER, G. C. et al. Wound repair and regeneration. Nature, v. 453, n. 7193 , p. 31421, May 2008. ISSN 1476-4687. Disponível em: < https://www.ncbi.nlm.nih.gov/pubmed/18480812 >.

BOULTON, A. J. et al. The global burden of diabetic foot disease. Lancet, v. 366, n. 9498, p. 1719-24, Nov 2005. ISSN 1474-547X. Disponível em: < https://www.ncbi.nlm.nih.gov/pubmed/16291066 >.

BALTZIS, D.; ELEFTHERIADOU, I.; VEVES, A. Pathogenesis and treatment of impaired wound healing in diabetes mellitus: new insights. Adv Ther, v. 31, n. 8, p. 817-36, Aug 2014. ISSN 1865-8652. Disponível em: < https://www.ncbi.nlm.nih.gov/pubmed/25069580 >.

KRONER, A. et al. TNF and increased intracellular iron alter macrophage polarization to a detrimental M1 phenotype in the injured spinal cord. Neuron, v. 83, n. 5, p. 1098116, Sep 2014. ISSN 1097-4199. Disponível em: < https://www.ncbi.nlm.nih.gov/pubmed/25132469 $>$. 

acute and chronic wounds. Wound Repair Regen, v. 4, n. 4, p. 411-20, Oct 1996. ISSN 1067-1927. Disponível em: < https://www.ncbi.nlm.nih.gov/pubmed/17309691 >.

GHISLETTI, S. et al. Identification and characterization of enhancers controlling the inflammatory gene expression program in macrophages. Immunity, v. 32, n. 3, p. 31728, Mar 2010. ISSN 1097-4180. Disponível em: < https://www.ncbi.nlm.nih.gov/pubmed/20206554 >.

BABU, M. et al. Differential Promoter Methylation of Macrophage Genes Is Associated With Impaired Vascular Growth in Ischemic Muscles of Hyperlipidemic and Type 2 Diabetic Mice: Genome-Wide Promoter Methylation Study. Circ Res, v. 117, n. 3, p. 289-99, Jul 2015. ISSN 1524-4571. Disponível em: < https://www.ncbi.nlm.nih.gov/pubmed/26085133 >. Chem Soc, v. 89, n. 18, p. 4808-9, Aug 1967. ISSN 0002-7863. Disponível em: < https://www.ncbi.nlm.nih.gov/pubmed/6074800 >.

BOLZÁN, A. D.; BIANCHI, M. S. Genotoxicity of streptozotocin. Mutat Res, v. 512, n. 23, p. 121-34, Dec 2002. ISSN 0027-5107. Disponível em: < https://www.ncbi.nlm.nih.gov/pubmed/12464347 >.

WANG, Z.; GLEICHMANN, H. GLUT2 in pancreatic islets: crucial target molecule in diabetes induced with multiple low doses of streptozotocin in mice. Diabetes, v. 47, n. 1, p. 50-6, Jan 1998. ISSN 0012-1797. Disponível em: < https://www.ncbi.nlm.nih.gov/pubmed/9421374 $>$.

BENNETT, R. A.; PEGG, A. E. Alkylation of DNA in rat tissues following administration of streptozotocin. Cancer Res, v. 41, n. 7, p. 2786-90, Jul 1981. ISSN 0008-5472. Disponível em: <https://www.ncbi.nlm.nih.gov/pubmed/6454479 $>$.

NUKATSUKA, M. et al. Importance of the concentration of ATP in rat pancreatic beta cells in the mechanism of streptozotocin-induced cytotoxicity. J Endocrinol, v. 127, n. 1, p. 161-5, Oct 1990. ISSN 0022-0795. Disponível em: < https://www.ncbi.nlm.nih.gov/pubmed/2151740 >.

CARLOS, D. et al. Mitochondrial DNA Activates the NLRP3 Inflammasome and Predisposes to Type 1 Diabetes in Murine Model. Front Immunol, v. 8, p. 164, 2017. ISSN 1664-3224. Disponível em: < https://www.ncbi.nlm.nih.gov/pubmed/28289409 >.

TALAHALLI, R. et al. Increased synthesis of leukotrienes in the mouse model of diabetic retinopathy. Invest Ophthalmol Vis Sci, v. 51, n. 3, p. 1699-708, Mar 2010. ISSN 1552-5783. Disponível em: < https://www.ncbi.nlm.nih.gov/pubmed/19834040 >. 

immune diabetes induced by multiple low-dose streptozotocin. J Appl Physiol (1985), v. 98 , n. 3, p. 1064-9, Mar 2005. ISSN 8750-7587. Disponível em: < https://www.ncbi.nlm.nih.gov/pubmed/15703165 >.

PEPINO, M. Y. et al. Structure-function of CD36 and importance of fatty acid signal transduction in fat metabolism. Annu Rev Nutr, v. 34, p. 281-303, 2014. ISSN 15454312. Disponível em: < https://www.ncbi.nlm.nih.gov/pubmed/24850384 >.

SAMOVSKI, D. et al. Regulation of AMPK activation by CD36 links fatty acid uptake to $\beta$-oxidation. Diabetes, v. 64, n. 2, p. 353-9, Feb 2015. ISSN 1939-327X. Disponível em: < https://www.ncbi.nlm.nih.gov/pubmed/25157091 >. maturation stage and inflammatory response. J Immunol, v. 172, n. 7, p. 4410-7, Apr 2004. ISSN 0022-1767. Disponível em: < https://www.ncbi.nlm.nih.gov/pubmed/15034056 >.

FALANGA, V. Wound healing and its impairment in the diabetic foot. Lancet, v. 366, n. 9498, p. 1736-43, Nov 2005. ISSN 1474-547X. Disponível em: < https://www.ncbi.nlm.nih.gov/pubmed/16291068 >.

HINK, U. et al. Mechanisms underlying endothelial dysfunction in diabetes mellitus: therapeutic implications. Treat Endocrinol, v. 2, n. 5, p. 293-304, 2003. ISSN 11756349. Disponível em: < https://www.ncbi.nlm.nih.gov/pubmed/15981946 >.

JONES IV, A. R. et al. Type 1 diabetes alters lipid handling and metabolism in human fibroblasts and peripheral blood mononuclear cells. PLoS One, v. 12, n. 12, p. e0188474, 2017. ISSN 1932-6203. Disponível em: < https://www.ncbi.nlm.nih.gov/pubmed/29206239 >.

GUNAWARDANA, S. C.; PISTON, D. W. Reversal of type 1 diabetes in mice by brown adipose tissue transplant. Diabetes, v. 61, n. 3, p. 674-82, Mar 2012. ISSN 1939-327X. Disponível em: < https://www.ncbi.nlm.nih.gov/pubmed/22315305 >.

$\mathrm{CHOI}, \mathrm{S}$. H. et al. Lipoprotein accumulation in macrophages via toll-like receptor-4dependent fluid phase uptake. Circ Res, v. 104, n. 12, p. 1355-63, Jun 2009. ISSN 15244571. Disponível em: < https://www.ncbi.nlm.nih.gov/pubmed/19461045 >.

VOLPE, C. M. et al. The production of nitric oxide, IL-6, and TNF-alpha in palmitatestimulated PBMNCs is enhanced through hyperglycemia in diabetes. Oxid Med Cell Longev, v. 2014, p. 479587, 2014. ISSN 1942-0994. Disponível em: < https://www.ncbi.nlm.nih.gov/pubmed/24803982 >. 

monocyte as biomarker for inflammatory diseases. Biomark Res, v. 2, n. 1, p. 1, Jan 2014. ISSN 2050-7771. Disponível em: < https://www.ncbi.nlm.nih.gov/pubmed/24398220 >.

LIU-BRYAN, R. et al. Innate immunity conferred by Toll-like receptors 2 and 4 and myeloid differentiation factor 88 expression is pivotal to monosodium urate monohydrate crystal-induced inflammation. Arthritis Rheum, v. 52, n. 9, p. 2936-46, Sep 2005. ISSN 0004-3591. Disponível em: < https://www.ncbi.nlm.nih.gov/pubmed/16142712 >.

DAVIS, J. E. et al. TIr-4 deficiency selectively protects against obesity induced by diets high in saturated fat. Obesity (Silver Spring), v. 16, n. 6, p. 1248-55, Jun 2008. ISSN 1930-7381. Disponível em: < https://www.ncbi.nlm.nih.gov/pubmed/18421279 >.

RIVOLLIER, A. et al. Inflammation switches the differentiation program of Ly6Chi monocytes from antiinflammatory macrophages to inflammatory dendritic cells in the colon. J Exp Med, v. 209, n. 1, p. 139-55, Jan 2012. ISSN 1540-9538. Disponível em: < https://www.ncbi.nlm.nih.gov/pubmed/22231304 >.

CHEN, M. et al. The role of hyperglycemia in FAT/CD36 expression and function. Pediatr Surg Int, v. 22, n. 8, p. 647-54, Aug 2006. ISSN 0179-0358. Disponível em: < https://www.ncbi.nlm.nih.gov/pubmed/16838191 >.

BRONDANI, L. A. et al. The UCP1 -3826A/G polymorphism is associated with diabetic retinopathy and increased UCP1 and MnSOD2 gene expression in human retina. Invest Ophthalmol Vis Sci, v. 53, n. 12, p. 7449-57, Nov 2012. ISSN 1552-5783. Disponível em: < https://www.ncbi.nlm.nih.gov/pubmed/23033381 >.

STOSIO, M. et al. Genetic background of aberrant thermogenin expression (UCP1) in obesity leading to metabolic syndrome. Postepy Hig Med Dosw (Online), v. 70, n. 0, p. 1389-1403, Dec 2016. ISSN 1732-2693. Disponível em: < https://www.ncbi.nlm.nih.gov/pubmed/28100847 >.

FLEMING, B. D.; MOSSER, D. M. Regulatory macrophages: setting the threshold for therapy. Eur J Immunol, v. 41, n. 9, p. 2498-502, Sep 2011. ISSN 1521-4141. Disponível em: $\langle$ http://www.ncbi.nlm.nih.gov/pubmed/21952805 $>$. isoenzymes during normal and diabetes-impaired skin repair. J Invest Dermatol, v. 121, n. 6, p. 1544-51, Dec 2003. ISSN 0022-202X. Disponível em: < https://www.ncbi.nlm.nih.gov/pubmed/14675208 >. 
CAMPBELL, L. et al. Local arginase 1 activity is required for cutaneous wound healing. J Invest Dermatol, v. 133, n. 10, p. 2461-70, Oct 2013. ISSN 1523-1747. Disponível em: < https://www.ncbi.nlm.nih.gov/pubmed/23552798 >.

SOUZA, D. G. et al. The required role of endogenously produced lipoxin A4 and annexin-1 for the production of IL-10 and inflammatory hyporesponsiveness in mice. J Immunol, v. 179, n. 12, p. 8533-43, Dec 2007. ISSN 0022-1767. Disponível em: < https://www.ncbi.nlm.nih.gov/pubmed/18056401 >.

CHAWLA, A. Control of macrophage activation and function by PPARs. Circ Res, v. 106, n. 10, p. 1559-69, May 2010. ISSN 1524-4571. Disponível em: < https://www.ncbi.nlm.nih.gov/pubmed/20508200 >.

VATS, D. et al. Oxidative metabolism and PGC-1beta attenuate macrophage-mediated inflammation. Cell Metab, v. 4, n. 1, p. 13-24, Jul 2006. ISSN 1550-4131. Disponível em: $<$ https://www.ncbi.nlm.nih.gov/pubmed/16814729 $>$.

DIVAKARUNI, A. S. et al. Etomoxir Inhibits Macrophage Polarization by Disrupting CoA Homeostasis. Cell Metab, Jun 2018. ISSN 1932-7420. Disponível em: < https://www.ncbi.nlm.nih.gov/pubmed/30043752 >.

NOMURA, M. et al. Fatty acid oxidation in macrophage polarization. Nat Immunol, v. 17, n. 3, p. 216-7, Mar 2016. ISSN 1529-2916. Disponível em: < https://www.ncbi.nlm.nih.gov/pubmed/26882249 >.

VAN DEN BOSSCHE, J.; O'NEILL, L. A.; MENON, D. Macrophage Immunometabolism: Where Are We (Going)? Trends Immunol, v. 38, n. 6, p. 395-406, 06 2017. ISSN 14714981. Disponível em: < https://www.ncbi.nlm.nih.gov/pubmed/28396078 >.

MUIR, L. A. et al. Rapid adipose tissue expansion triggers unique proliferation and lipid accumulation profiles in adipose tissue macrophages. J Leukoc Biol, Mar 2018. ISSN 1938-3673. Disponível em: < https://www.ncbi.nlm.nih.gov/pubmed/29493813 >. protective! J Clin Invest, v. 128, n. 3, p. 910-912, Mar 2018. ISSN 1558-8238. Disponível em: < https://www.ncbi.nlm.nih.gov/pubmed/29457787 >. 2013, p. 585897, 2013. ISSN 2314-6745. Disponível em: < https://www.ncbi.nlm.nih.gov/pubmed/23841103 >. 

cutaneous wound healing in mice. Wound Repair Regen, v. 21, n. 3, p. 464-72, 2013 May-Jun 2013. ISSN 1524-475X. Disponível em: < https://www.ncbi.nlm.nih.gov/pubmed/23627416 >. macrophage phenotype and improves healing in type 2 diabetes. Diabetes, v. 62, n. 7, p. 2579-87, Jul 2013. ISSN 1939-327X. Disponível em: < https://www.ncbi.nlm.nih.gov/pubmed/23493576 >. B4 (LTB. Clin Immunol, v. 190, p. 74-83, May 2018. ISSN 1521-7035. Disponível em: < https://www.ncbi.nlm.nih.gov/pubmed/28965882 >. n. 1, p. 59-67, Jan 2010. ISSN 1938-3673. Disponível em: < https://www.ncbi.nlm.nih.gov/pubmed/20052800 >.

NOVAK, M. L.; KOH, T. J. Phenotypic transitions of macrophages orchestrate tissue repair. Am J Pathol, v. 183, n. 5, p. 1352-63, Nov 2013. ISSN 1525-2191. Disponível em: < https://www.ncbi.nlm.nih.gov/pubmed/24091222 >. and Effector Mechanisms. Mediators Inflamm, v. 2015, p. 816460, 2015. ISSN 14661861. Disponível em: < https://www.ncbi.nlm.nih.gov/pubmed/26089604 >. Stimulating Macrophage Polarization to M1 in Diabetes. Sci Rep, v. 6, p. 36416, Nov 2016. ISSN 2045-2322. Disponível em: < https://www.ncbi.nlm.nih.gov/pubmed/27805071 >. 